\title{
1 \\ A CONSTRUÇÃO DA SAÚDE \\ NA ESCOLA: UMA AÇÃO \\ PREVENTIVA DE DOENÇAS
}

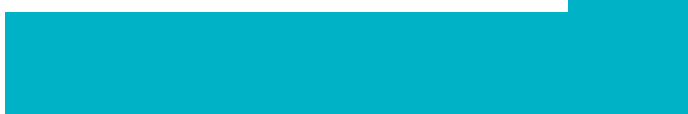 \\ Angelita Alves Almeidal \\ - Claudia Márcia Fricks Jordao Belonia Terra ${ }^{1}$ \\ - Claudiana do Nascimento ${ }^{1}$ \\ - Cristiani Jordão Gomes de Almeida ${ }^{I}$ \\ - Danielle Correia Santana ${ }^{1}$ \\ - Kamila Batista Nunes Viana ${ }^{1}$ \\ - Luciana Tonon Fontana ${ }^{1}$ \\ - Marciana dos Santos Silva Ventura ${ }^{I}$ \\ - Rita Maria Fernandes Leal Moreira Cacemiro ${ }^{1}$
}

\section{INTRODUÇÃO}

Os programas de saúde na escola possuem precedentes históricos. Como a escola se tornou o principal meio de alcançar a população, muito se discute atualmente de como isso pode ser utilizado para disseminar conhecimentos em saúde e garantir direitos básicos aos cidadãos.

A saúde surge como um direito fundamental, e a Constituição Federal do ano de 1988 consagra este direito. $\mathrm{O}$ direito à saúde é indisponível, ou seja, não pode ser alienado ou negado à nenhuma pessoa.

\begin{abstract}
196. A saúde é direito de todos e dever do Estado, garantido mediante políticas sociais e econômicas que visem à redução do risco de doença e de outros agravos e ao acesso universal e igualitário às ações e serviços para sua promoção, proteção e recuperação.

Art. 197. São de relevância pública as ações e serviços de saúde, cabendo ao Poder Público dispor, nos termos da lei, sobre sua regulamentação, fiscalização e controle, devendo sua execução ser feita diretamente ou através de terceiros e, também, por pessoa física ou jurídica de direito privado.

Art. 198. As ações e serviços públicos de saúde integram uma rede regionalizada e hierarquizada e constituem um sistema único, organizado de acordo com as seguintes diretrizes: I - descentralização, com direção única em cada esfera de governo; II - atendimento integral, com prioridade para as atividades preventivas, sem prejuízo dos serviços assistenciais; III - participação da comunidade (BRASIL, 1988, s/p).
\end{abstract}

Saúde e educação são invocadas constantemente quando se trata das condições de vida. A interação entre eles, onde quer que estejam - escola ou saúde - é uma forma importante de alcançar qualidade de vida. A

$1 \quad$ Faculdade Vale do Cricaré (FVC), São Mateus - Espírito Santo. 
construção de práticas pedagógicas relacionadas a essa interação é um grande desafio diante das exigências da escola. É preciso discutir os conceitos que embasam as atividades de saúde como práticas pedagógicas, explicando-os a todos os envolvidos (CARVALHO, 2015).

A transmissão de conhecimentos em saúde na escola não alcança apenas os alunos e professores, mas toda a sociedade, já que é na escola que as futuras gerações são construídas. Para isso, inserir na grade curricular conhecimentos básicos de saúde, torna-se extremamente importante, ainda mais considerando que as gerações presentes terão mais domínio sobre tecnologias.

Dado que hábitos, atitudes e crenças formadas na infância e adolescência têm maior probabilidade de persistir na vida adulta e que a maioria das crianças e adolescentes brasileiros frequenta a escola $(98,6 \%$ das crianças de 6 a 14 anos e 85,0\% dos adolescentes na idade 15-17), considera-se os alunos nas comunidades escolares, um alvo para o desenvolvimento de medidas preventivas (LOPES et al., 2018).

Para Silva, et al. (2018), diferentes conceitos de promoção da saúde podem ser divididos em dois grupos: o comportamental e o outro relacionado à qualidade de vida. Na primeira, a promoção da saúde consiste em atividades que visam a mudança de comportamento dos respondentes, com foco nos componentes educacionais, principalmente relacionados às ameaças comportamentais passíveis de mudança. A segunda parte do entendimento de que a saúde é o produto de diversos fatores relacionados à qualidade de vida, incluindo alimentação, nutrição, moradia e padrões de saneamento adequados; trabalho; acesso à educação ao longo da vida; ambiente físico puro; apoiar redes sociais; estilo de vida responsável; e saúde adequada.

O Programa Saúde na Escola (PSE), aparece como alternativa aos problemas que assolam à saúde do público escolar. Não apenas importando questões relacionadas á educação em saúde, mas também os cuidados básicos que devem ser dispensados à população e que se torna mais acessível nesse campo. Introduzir práticas educacionais voltadas á saúde alimentar, saúde mental, instruções básicas de convivência, tudo isso colabora para garantir o espaço social de cada um e preservar a saúde da população.

Sobre as características do PSE além das áreas abrangidas pelo programa, Machado, et al. (2015), diz que o programa é hoje uma das principais políticas públicas para a infância e juventude. Os seus elementos incluem avaliação clínica e nutricional, promoção da alimentação saudável, avaliação oftalmológica, bem como atividades no domínio da educação ao longo da vida na área da saúde, atividade física e saúde, divulgação da cultura da prevenção no ambiente escolar e inclusão de temas de educação para a saúde.

Para Lopes, et al. (2018), as políticas e programas de saúde pública e educação são fundamentais para a formação dos cidadãos e a melhoria da qualidade de vida e saúde da população. Um melhor nível de educação está associado a uma população mais saudável, da mesma forma que uma população saudável tem mais oportunidades de apropriar-se de conhecimentos e conhecimentos da educação formal e informal. A escola, além de proporcionar conhecimentos sobre saúde, organizados em disciplinas, deve também educar e desenvolver valores e atitudes críticas relacionadas à realidade social e aos estilos de vida, nos processos de aquisição de competências que sustentem a aprendizagem ao longo da vida, e isso promova autonomia e empoderamento na promoção da saúde.

Considerando os benefícios de se construir bases de saúde na escola e introduzir conhecimentos relacionados a área na educação básica, é viável insistir que se trata de uma política pública de saúde e educação que irá afetar inúmeras outras áreas, incluindo o emprego, desenvolvimento e renda, pois os ambientes escolares equipados de profissionais da área, gerarão novos cargos e novas funções essenciais.

Com isso, é objetivo do presente artigo apresentar a construção da saúde na escola como alternativa de 
combater doenças. Através da temática observa-se o Programa Saúde na Escola, que é uma realidade no Brasil e compreende várias políticas de saúde para o alunado. Além do mais, cabe ressaltar de que maneira as ações de saúde apresentam seus resultados positivos no ambiente escolar e na sociedade, trabalhando pontos como alimentação saudável, saúde física e corporal e saúde mental.

\section{O PROGRAMA SAÚDE NA ESCOLA (PSE)}

O programa saúde na escola é apresentado de inúmeras formas por diversos autores, e está presente na vida educacional básica do brasileiro. Para o Ministério da Saúde (2009) o Programa Saúde na Escola (PSE) visa integrar e vincular permanentemente educação e saúde, melhorando a qualidade de vida da população brasileira. Como consolidar essa atitude nas escolas? Essa é a questão que levou a trabalhar a metodologia dos programas de educação e saúde que seriam implantados em projetos de ensino nas Escolas.

\subsection{A IMPORTÂNCIA DO PROGRAMA SAÚDE NA ESCOLA (PSE)}

Munir as escolas de ações que envolvem saúde em conjunto com a educação é um objetivo sistemático. A forma como se emprega o conhecimento de educação em saúde pode ser contestada à partir do momento que há divergências nos campos do conhecimento, entretanto não se trata apenas de ação de transmissão de conhecimentos, mas garantir a presença de profissionais capacitados nas escolas é uma forma de prevenir doenças.

O PSE visa contribuir para a formação integral dos alunos por meio de ações de promoção, prevenção e saúde para suprir as fragilidades que ameaçam o desenvolvimento integral de crianças e jovens da rede pública de ensino. São destinatários do PSE alunos do ensino fundamental, gestores e especialistas em educação e saúde, comunidade escolar e, de forma mais ampla, alunos da Rede Federal de Educação Profissional e Técnica e Educação de Jovens e Adultos (MINISTÉRIO DA EDUCAÇÃO, 2009).

O profissional nutricionista por exemplo, trabalhando questões relacionadas à obesidade infantil, que é um problema recorrente. Trata-se de ação que pode ser conjunta com as disciplinas de ciências, tanto no campo do conhecimento quanto no campo de ação do profissional, executando todas as ações para trabalhar o problema em questão. Infelizmente a ação parte apenas para o campo do atendimento, através de programas nutricionais, mas que não são acentuados com a aplicação de disciplinas que efetivem as ações propostas.

O Programa Nacional de Alimentação Escolar é um dos mais antigos programas sociais do governo brasileiro, considerado um dos maiores programas de universalização da educação no mundo. Tem como objetivo contribuir para o crescimento e desenvolvimento biopsicossocial, aprendizagem, desempenho escolar e modelagem de práticas alimentares saudáveis de alunos por meio de atividades de educação nutricional e de educação nutricional e fornecimento de refeições adequadas às suas necessidades nutricionais durante o período letivo. Vale ressaltar que em 2009 o Programa atendeu 47 milhões de alunos (SANTOS et al., 2012).

A gravidez na adolescência é outro problema que está incluído na grade dos recorrentes, pois causa evasão escolar, corrompe uma parte importante da vida do adolescente além de agravar possíveis problemas 
ligados à saúde mental. O programa saúde trás a figura do psicólogo para o ambiente escolar, entretanto, esta é uma ação que necessita de investimento no campo do conhecimento. Pouco se fala de sexo, sexualidade e conhecimentos corporais nas salas de aula, menos ainda é falado com propriedade e conhecimento pelas famílias brasileiras, o que acaba deixando o adolescente no escuro. Este problema pode ser superado a partir de ações de instrução no ambiente escolar.

A gravidez na adolescência é frequentemente considerada única, uniforme e quase atemporal; um evento precoce relacionado às camadas mais pobres e menos instruídas da população. Essa homogeneização torna impossível compreender a miríade de realidades e diferenças vividas pelas jovens mães. Questões-chave na vida dessas jovens, como o desejo de engravidar, formar famílias nucleares e mudar seu status social, são frequentemente esquecidas (VIEIRA et al., 2017).

Segundo Oliveira, et al. (2010), questões instrutivas em sala de aula podem cobrir o vácuo deixado pelas famílias que, transbordadas pelo conservadorismo e por concepções erradas do assunto sexo e sexualidade, não tratam desses assuntos no cotidiano familiar. Não se trata de questão generalizada, mas é notório que a maior parte das famílias não consegue trabalhar sexo com medo de incentivar, o que tem um efeito reverso, já que as questões importantes acerca do assunto não são tratadas, e a banalização é quase inevitável.

\subsection{AÇÕES DO PROGRAMA SAÚDE NA ESCOLA}

Apesar das questões ainda não tratadas no ambiente escolar, o PSE já está sendo executado desde o ano de 2007 e possui na sua lista uma gleba imensa de especialidades. Para o Ministério da Educação (2009), o alcance dos objetivos e do sucesso do PSE, é fundamental entender a educação integral como um conceito que inclui a proteção, a atenção e o desenvolvimento integral da comunidade escolar. No campo da saúde, a prática das equipes de Saúde da Família inclui a prevenção, promoção, recuperação e manutenção da saúde de indivíduos e grupos de pessoas. Para alcançar o descrito acima destaca-se os cinco componentes sob os quais o PSE foi criado:

Avaliação das Condições de Saúde das crianças, adolescentes e jovens que estão na escola pública; b) Promoção da Saúde e de atividades de Prevenção; c) Educação Permanente e Capacitação dos Profissionais da Educação e da Saúde e de Jovens. d) Monitoramento e Avaliação da Saúde dos Estudantes; e) Monitoramento e Avaliação do Programa (MINISTÉRIO DA EDUCAÇÃO, 2009).

Dentro do PSE, é importante destacar o projeto municipal, que é um dos requisitos do processo adesivo como "leitura técnica" da situação urbana, visando iniciar o processo de construção coletiva das atividades voltadas à implantação do PSE. Documento baseado em informações de diversas fontes disponíveis em bancos de dados do poder público federal, estadual e municipal. A proposta identifica prioridades e aspectos que requerem um redimensionamento e/ou qualificação na área da educação e saúde.

Em aparte específico da área de atuação, o projeto municipal identifica áreas de responsabilidade, definidas de acordo com a área de abrangência das equipes da Estratégia Saúde da Família (ESF), e define um conjunto de escolas incluídas em cada território, apresentando informações sobre:

O diagnóstico situacional com as questões referentes a determinantes sociais, cenário epidemiológico e modalidades de ensino das escolas vinculadas às equipes da ESF e que atuarão no PSE;

O mapeamento da Rede SUS de AB/SF e das Redes de Ensino - estadual e municipal, criando espaços comuns, os territórios de responsabilidade; 
As atribuições das equipes da ESF e das escolas em cada um dos territórios de responsabilidade, quantificando o número de escolas, de estudantes de cada estabelecimento e as questões prioritárias do perfil desses alunos. Definição dos responsáveis das áreas da saúde e da educação pelo projeto dentro de cada território;

A identificação das instituições de ensino atendidas pelo Programa Saúde na Escola. Definição do professor responsável pela articulação das ações de prevenção e promoção da saúde na escola (MINISTÉRIO DA EDUCAÇÃ̃, 2009).

E ainda sobre as ações do PSE, o Ministério da Educação (2009) enfatiza que a agenda de educação e saúde é uma estratégia fundamental para a implementação de ações colaborativas em áreas urbanas. Seleciona-se o "recorte" do território, integrando escolas e unidades de saúde para criar a articulação das práticas. A agenda identificará propostas comunitárias para os microterritórios onde as escolas estão localizadas, refletindo as expectativas da comunidade sobre a interface educação e saúde. Por meio do diálogo entre a comunidade escolar e a equipe da Estratégia Saúde da Família, o programa de educação e saúde inclui o diálogo entre diferentes setores da sociedade e os programas/políticas já desenvolvidas na escola e com os parceiros locais.

E dessa forma, as ações do PSE seguem sendo desenvolvidas e estruturadas nas escolas, garantindo o espaço e as contribuições à sociedade. Gerando atendimentos e alcançando à população como determina à Carta Magna. Essas ações que acontecem nas escolas públicas, se inserem em um contexto de extrema desigualdade social, atingindo áreas marginalizadas e que historicamente foram esquecidas pelo Estado.

\section{A SAÚDE NA ESCOLA PREVENINDO DOENÇAS}

Não é novidade que o vínculo entre saúde e educação é reconhecido. De acordo com o argumento desta estreita ligação, há pelo menos um consenso entre as duas áreas: uma boa educação está associada a uma população mais saudável, e uma população saudável tem mais probabilidade de aprender sobre educação formal e informal. Dependendo de onde é falado e quais tintas são usadas, todos os tipos de discursos e cenários podem ser encontrados, ou, em outras palavras, sob este argumento, cabem várias abordagens sobre o assunto (CASEMIRO et al., 2014).

As ações de saúde na escola apresentam à sociedade inúmeros benefícios. Desde a instrução das gerações futuras sobre práticas essenciais de saúde até o acesso à maior parcela da população à serviços essenciais. Introduzir dentro das disciplinas da área da saúde matérias relacionadas a práticas preventivas de doenças de atingir toda á sociedade, instrumentalizando os alunos para serem difusores das boas e novas práticas.

A escola nem sempre foi um espaço para todos. Antes da democratização do ensino promovida recentemente no Brasil, a escola era elitizada, com pouco espaço para as classes mais abastadas socialmente, que por sua vez era forçada a dispensar sua força apenas no campo laboral, e não tinham tempo para os estudos. Era muito comum a família não incentivar crianças e adolescentes aos estudos por necessitarem da mão de obra dos mesmos para subsistir.

De acordo com Carvalho (2004), não se pode negar que, embora tenham menos de 40 anos, os esforços para promover o acesso universal ao ensino fundamental por oito anos (antiga primeira série) são pouca ou nenhuma polêmica. Já está consolidada a visão de que o acesso a esse segmento da educação escolar é um 
direito público, cujo gozo não pode ser impedido por nenhum exame opcional, como o vestibular, até então vigente. A polêmica que posteriormente mobilizou a comunidade educacional e a opinião pública parece ter se espalhado para outras esferas, notadamente as políticas públicas destinadas a regular o fluxo e reduzir as taxas de evasão - por exemplo, a continuidade do desenvolvimento e a criação de escolas.

Com um tempo se deu a construção de uma escola que poderia abrigar todos, entretanto os métodos permaneceram os mesmos, não abraçando o alunado das diferentes áreas da sociedade, não trabalhando questões importantes como as diferenças humanas e como elas influenciam no sistema de ensino-aprendizagem. Eis que se deu a primeira barreira para a construção de uma escola democrática, aberta e sem distinção de classes ou quaisquer situações que pudessem gerar desprezo e constrangimento ao discente.

Não existe atualmente uma Declaração de Direitos para dar um exemplo convincente que não reconheça o direito à educação - na verdade, da sociedade para a sociedade - primeiro no ensino fundamental, depois no ensino médio e gradualmente até na universidade. Para além da sua eficácia normativa, devem-se ter em consideração os aspectos que se prendem com a garantia deste direito, tanto ao nível da oferta como do tipo de disposição que o poder público exige para o cumprir em caso de oferta regular ou insuficiente, bem como quanto ao papel do Estado na concretização a exigibilidade dos direitos sociais, bem como a qualidade do papel social que esta tarefa propõe (SANTOS, 2019).

Para tanto, no que se refere a garantia constitucional à educação, a Carta Magna de 1988 dispõe que:

205. A educação, direito de todos e dever do Estado e da família, será promovida e incentivada com a colaboração da sociedade, visando ao pleno desenvolvimento da pessoa, seu preparo para o exercício da cidadania e sua qualificação para o trabalho.

Art. 206. O ensino será ministrado com base nos seguintes princípios: I - igualdade de condições para o acesso e permanência na escola; II - liberdade de aprender, ensinar, pesquisar e divulgar o pensamento, a arte e o saber; III - pluralismo de idéias e de concepções pedagógicas, e coexistência de instituições públicas e privadas de ensino; IV - gratuidade do ensino público em estabelecimentos oficiais; $V$ - valorização dos profissionais da educação escolar, garantidos, na forma da lei, planos de carreira, com ingresso exclusivamente por concurso público de provas e títulos, aos das redes públicas; VI gestão democrática do ensino público, na forma da lei; VII - garantia de padrão de qualidade. VIII - piso salarial profissional nacional para os profissionais da educação escolar pública, nos termos de lei federal. Parágrafo único. A lei disporá sobre as categorias de trabalhadores considerados profissionais da educação básica e sobre a fixação de prazo para a elaboração ou adequação de seus planos de carreira, no âmbito da União, dos Estados, do Distrito Federal e dos Municípios (BRASIL, 1988, s/p).

Formar novos cidadãos através da escola não é uma tarefa muito fácil, contudo é imprescindível atentar-se às novas necessidades e introduzir o preparo através da educação básica. Como se trata do vínculo mais próximo que se tem com as futuras gerações, tornar o ambiente escolar uma casa de formação de novos cidadãos capacitados se faz extremamente necessário. Através da educação básica que se pode garantir que todos, no futuro, possuam conhecimentos básicos acerca de assuntos necessários aos seres humanos, como por exemplo à saúde.

De acordo com Bydlowski, et al. (2011), A população brasileira possui características especiais que 
ainda refletem o período colonial até os dias de hoje. A condição de submissão está entrelaçada com os processos democráticos em curso. Isso dificulta o alcance de melhores condições de vida e saúde, ou seja, uma situação em que todos tenham as mesmas chances de alimentação, educação, saúde, enfim, uma sobrevivência digna. Além disso, no Brasil, o atual modelo de atenção à saúde, o modelo biomédico (medicina curativa e preventiva), não se mostra eficaz na melhoria da saúde, pois não leva em conta o impacto das precárias condições de saúde aqui mencionadas.

A promoção da saúde é considerada uma importante estratégia no processo de atenção à saúde e à doença, visando fortalecer o caráter promocional e preventivo. Uma das estratégias mais eficazes que contribuem para a promoção da saúde é a combinação de apoios educacionais e ambientais, abrangendo não só as dimensões individual, mas também organizacional e coletiva, visando, assim, atividades e condições de vida que favoreçam a saúde. Nesse sentido, a educação nutricional pode ser considerada um elemento decisivo na promoção da saúde (YAKOTA et al., 2010).

Um aluno que desde cedo está ambientado à práticas alimentares saudáveis, que em tenra idade conhece a importância de cuidar da própria saúde recebendo instruções de higiene pessoal e sabendo das fases do próprio corpo, estará muito mais distante da realidade do adoecimento precoce ou de doenças que se desenvolvem com o envelhecimento. Exceto em casos onde a pessoa já nasce com a doença, seria uma solução forte para reduzir a sobrecarga dos hospitais e demais casas de saúde pública.

Nessa perspectiva, Yakota, et al. (2010) ainda afirma que a escola é um espaço privilegiado para a construção e consolidação de práticas alimentares saudáveis para as crianças, por ser um ambiente no qual atividades voltadas à educação em saúde podem ter grande repercussão. Nesse contexto, todas as dimensões da aprendizagem são levadas em consideração: o ensino, as relações casa-escola-comunidade e o ambiente físico e emocional, para que possam beneficiar os alunos nas etapas básicas de suas vidas: infância e adolescência.

$\mathrm{Na}$ escola também se incentiva às práticas esportivas através da disciplina de educação física. Praticar esportes ou abandonar a vida sedentária é uma das melhores formas de conquistar imunidade para o organismo, e de tal forma ter uma vida mais saudável e livre de adoecimentos.

Entretanto, muitas práticas culturais são reforçadas por seus efeitos imediatos, mesmo que levem a sérios problemas para os grupos sociais no longo prazo. Exemplos de práticas culturais prejudiciais incluem: estilo de vida sedentário, dependência de drogas e violência. Embora prejudiciais, a característica comum dessas práticas culturais é que são reforçadas e sustentadas por consequências reforçadoras imediatas (naturais ou condicionadas) que geram punição apenas no longo prazo, para tal, surge a escola como espaço inclusive e preparado para lidar com tais situações, e promover uma revolução cultural benéfica (ORTI; CARRARA, 2012).

Dentro dos programas de saúde da mulher, tornou-se habitual trabalhar questões relacionadas à prevenção do câncer do colo do útero, que é um dos cânceres que mais matam mulheres anualmente no Brasil. As campanhas de vacinação contra o Papiloma vírus Humano (HPV) é um exemplo clássico para tornar a realidade das mulheres brasileiras menos custosa. Práticas a serem incentivadas como a realização dos exames de mama e Papanicolau, podem ser iniciadas desde cedo, ainda na escola

A Organização Mundial da Saúde (OMS) recomenda o uso da vacina contra o papilomavírus humano (HPV), principalmente para meninas de 9 a 14 anos, antes da atividade sexual. As evidências sugerem que a vacinação de meninas ( $>80 \%$ ) reduz o risco de infecção por HPV em meninos. As vacinas fornecem imu- 
nogenicidade e eficácia na prevenção do câncer cervical, que é causado principalmente pelo HPV 16 e 18 . $\mathrm{O}$ esquema de vacinação recomendado é de duas doses com um intervalo de seis meses entre a primeira e a segunda dose em indivíduos de 9 a 14 anos de idade (CARVALHO et al., 2019).

O HPV é causa de vários tipos de câncer: colo de útero, de vulva, vagina, pênis, ânus e orofaringe, bem como a causa das verrugas anogenitais. Estima-se que $99 \%$ dos casos de câncer de colo do útero estão ligados ao HPV, que é evitável com testes de triagem regulares e vacinas para o HPV. No Brasil, a prevalência geral estimada de HPV é de 54,6\%, e para os vírus de alto risco para o desenvolvimento de câncer é de 38,4\% (CARVALHO et al., 2019, p.11).

Ainda baseando-se na opinião de Carvalho AMC, et al. (2019), uma pausa de não mais de 12-15 meses é sugerida para completar o esquema de vacinação antes da atividade sexual. Se o intervalo entre as doses for inferior a cinco meses, a terceira dose deve ser administrada pelo menos seis meses após a primeira dose. O esquema de vacinação de três doses (0,1-2, 6 meses) é recomendado para maiores de 15 anos e para pessoas imunocomprometidas ou infectadas com o vírus da imunodeficiência (HIV).

Para a mulher, é importante abordagens desde tenra idade da vida sexual e das mudanças corporais. Existem casos de meninas de 8 ou 9 anos que já começam a menstruar, e nem sempre sabem do que se trata, o que pode causar uma imensa confusão na cabeça da criança. Profissionais ligados à saúde mental pode introduzir instruções acerca desses assuntos na vida escolar, reduzindo cada vez mais a desinformação e as possibilidades de gerar confusões na cabeça dos alunos.

Compreender os caminhos da construção social, cultural e histórica da sexualidade e do sexo é importante, pois se reflete na forma como os documentos públicos os focalizam. Como parte desse processo, as crianças foram identificadas como assexuadas, símbolos de pureza, privadas da capacidade de falar, ouvir e fazer perguntas sobre sexo. A fim de manter sua ignorância, tentamos distanciá-los de sua curiosidade, usando um padrão repressivo de comportamento (SFAIR SC, et al., 2015).

Sobre a saúde bucal, programas que levam profissionais dentistas as escolas, buscando incentivar os cuidados com os dentes e visando alertar como é importante manter a saúde da boca em dia. Várias doenças são contraídas através de maus hábitos de higiene bucal, inclusive através das cáries pode-se obter contato com enfermidades indesejadas.

Muitos estudos têm demonstrado que as doenças bucais podem ser prevenidas e controladas modificando seus fatores etiológicos. Em relação à cárie dentária, as medidas preconizadas para a sua prevenção baseiam-se essencialmente na educação e motivação do paciente para desorganizar a placa, reduzir a ingestão de açúcar e usar flúor. A educação, portanto, desempenha um papel preponderante no alcance da boa saúde bucal, facilitando o desenvolvimento da consciência crítica das pessoas sobre as causas de seus problemas, despertando o interesse e a responsabilidade pela manutenção da saúde (GARBIN et al., 2016).

Com todas essas possibilidades, é possível identificar as inúmeras formas indesejadas de se adquirir enfermidades e as melhores maneiras de trabalhar essas questões desde cedo com as gerações futuras, á fim de prevenir doenças e garantir uma qualidade de vida maior, promovendo uma revolução social nos campos da saúde e da educação. 


\section{CONSIDERAÇÕES FINAIS}

Considerando os objetivos desta pesquisa, conclui-se que a saúde na escola é uma porta para inúmeras problemáticas que são constantemente discutidas. Educação em saúde pode reduzir o agravamento de problemas sociais relacionados a enfermidades além de problemas que agravam questões financeiras e fomentam a desigualdade social.

As políticas de saúde dentro da escola levam à saúde as classes mais afastadas das mãos do Estado, o que melhora a densidade de pessoas que são alcançadas pelo serviço público. Serviço público de qualidade significa desenvolvimento humano e aumento da qualidade de vida, o que transmite através da educação uma melhor condição existencial para a sociedade.

Questões que são trabalhadas através do PSE são de grande importância quando se averígua que os dados colhidos apresentam melhoras. A redução da mortalidade infantil se deu pelas melhorias nos programas gestacionais, e de igual modo, resultados na luta contra o HPV e outras doenças que são trabalhadas no ambiente escolar, serão dados do futuro devido aos programas do PSE.

Com isso, é possível concluir que a escola se tornou o acesso mais eficaz do Estado para trabalhar mudanças á longo prazo com programas de saúde e educação. As futuras gerações são acessíveis, as escolas democratizadas desencadeiam um vínculo com quase toda à população, criando uma linha de transmissão de informações necessárias para manter a sociedade atenta e atrelada às possibilidades e participações nas atividades da sociedade civil organizada. 


\section{REFERÊNCIAS BIBLIOGRÁFICAS}

BRASIL. 1988. In: CONSTITUIÇÃO da República Federativa do Brasil de 1988. Brasília: Presidência da República. Disponível em: http://www.planalto.gov.br/ccivil_03/constituicao/constituicao.htm. Acesso em: 6 de ago. 2020 .

BYDLOWSKI CR, et al. Promoção da saúde e a formação cidadã: a percepção do professor sobre cidadania. Ciência \& Saúde Coletiva, 2011; 16(3): 1771-1780.

CARVALHO AMC, et al. Adesão à vacina HPV entre os adolescentes: revisão integrativa. Texto \& Contexto - Enfermagem, 2019; 28(1): 1-18.

CARVALHO FFB. A saúde vai à escola: a promoção da saúde em práticas pedagógicas. Physis Revista de Saúde Coletiva, 2015; 25(4): 1207-1227.

CASEMIRO JP, et al. Promover saúde na escola: reflexões a partir de uma revisão sobre saúde escolar na América Latina. Ciência \& Saúde Coletiva, 2014; 19(3): 829-840.

GARBIN CAS, et al. Saúde bucal na escola: avaliação do conhecimento dos pais e da condição de saúde bucal das crianças. RFO UPF, 2016; 21(1): 1-11.

LOPES IE, et al. Eixos de ação do Programa Saúde na Escola e Promoção da Saúde: revisão integrativa. Saúde debate, 2018; 42(118): 773-789.

MACHADO MFAS, et al. Programa saúde na escola: estratégia promotora de saúde na atenção básica no Brasil. Journal of Human Growth and Development, 2015; 25(3): 307-312.

MINISTÉRIO DA EDUCAÇÃO. 2009. In: PROGRAMA Saúde nas Escolas. Governo Federal: Brasília. Disponível em: http://portal.mec.gov.br/expansao-da-rede-federal/194-secretarias-112877938/secad-educacao-continuada-223369541/14578-programa-saude-nas-escolas. Acesso em: 8 de jul. 2020.

OLIVEIRA EFV, et al. Gravidez na adolescência e outros fatores de risco para mortalidade fetal e infantil no Município do Rio de Janeiro, Brasil. Cad. Saúde Pública, 2010; 26(3): 567-578.

ORTI NP, CARRARA K. Educação física escolar e sedentarismo infantil: uma análise comportamental. Arquivos Brasileiros de Psicologia, 2012; 64(3): 35-56.

SANTOS E. A educação como direito social e a escola como espaço protetivo de direitos: uma análise à luz da legislação educacional brasileira. Educação e Pesquisa, 2019; 45(1): 1-14.

SANTOS LAS, et al. O nutricionista no programa de alimentação escolar: avaliação de uma experiência de formação a partir de grupos focais. Revista de Nutrição, 2012; 25(1): 107-117.

SFAIR SC, et al. Educação sexual para adolescentes e jovens: mapeando proposições oficiais. Saúde Soc, 2015; 24(2): 620-632.

SILVA JP, et al. Promoção da saúde na educação básica: percepções dos alunos de licenciatura em enfermagem. Revista Gaúcha de Enfermagem, 2018; 39(1): 1-12.

VIEIRA EM, et al. Gravidez na adolescência e transição para a vida adulta em jovens usuárias do SUS. Revista de Saúde Pública, 2017; 51(25): 1-11.

YAKOTA RTC, et al. Projeto “a escola promovendo hábitos alimentares saudáveis": comparação de duas estratégias de educação nutricional no Distrito Federal, Brasil. Revista de Nutrição, 2010; 23(1): 37-47. 